\title{
Taking Things for Granted: Comments on Harman and Sherman
}

\author{
Thomas Kelly \\ Princeton University \\ tkelly@princeton.edu
}

I think that the phenomenon of taking things for granted is an interesting and important one. But it has received relatively little attention from either epistemologists or theorists of rationality. ${ }^{1}$ In putting this topic on the table in such a direct and forceful way, Harman and Sherman's paper opens up new avenues for exploration.

1. On any plausible view, there are some things that you are justified in taking for granted, and other things that you are not justified in taking for granted. ${ }^{2}$ One way in which someone might be subject to legitimate criticism for taking something for granted is this: what he or she takes for granted isn't true. (If you point out that something that I'm taking for granted is false, then I should stop taking it for granted.) It also seems that someone is subject to legitimate criticism for taking for granted something that it is unreasonable to think is true. (If you point out that something that I'm taking for granted is unlikely to be true given our evidence, then it seems like I should stop taking it for granted.) Putting these points together, one might think that a relevant norm here involves knowledge:

One should only take for granted what one knows.

In fact, I'm inclined to think that this is a genuine norm. "Don't take for granted things that you don't know to be true" has the ring of truth, at least to my ear. It's the

\footnotetext{
${ }^{1}$ A notable exception among the latter is Bratman (1999).

${ }^{2}$ Here as elsewhere, talk of 'justification' suggests something more akin to permission than to requirement or obligation. But plausibly, and although Harman and Sherman don't say this explicitly, there are some cases in which it's not only permissible to take something for granted but in which it would be impermissible or inappropriate not to do so. For example, consider a detective who is charged with solving some crime, but who spends his time reading philosophy journal articles in an attempt to get a better handle on the seemingly more fundamental question of whether it might all be one big dream. Such a detective is subject to criticism for not taking enough for granted: he is failing to take something for granted that he should take for granted, given his purposes, etc. Having noted this, I will set it aside in what follows.
} 
kind of thing that one might tell one's children and feel like one is both giving good advice and speaking the truth. Consider also the following faux paus, frequently committed by academics as well as others. Suppose that you are in a small group that is discussing politics, and a colleague is carrying on. It's clear from the way the colleague is carrying on that he's simply assuming or taking for granted that everyone else in the group shares his view about some issue. In fact, however, that assumption is false. Suppose that later on you point this out to your colleague: "You know, you were just assuming that everyone shared your view that $\mathrm{p}$, but so-and-so doesn't: in fact, she thinks that not-p". The colleague might react with surprise: "I didn't know that!--I was just taking it for granted that everyone there thought that p". No doubt, the colleague was genuinely ignorant of the fact that not everyone in the group shared his view. But it seems that, given that he didn't know that everyone else shared his view, he shouldn't have simply assumed that they did. One shouldn't take for granted things that one doesn't know to be true.

Thus, I'm inclined to endorse the "knowledge norm" for assuming or taking for granted. I do this not only because treating knowledge as the norm for various things is all the rage these days, and it would be nice to get in on the action, but because (at least in this case) that's where the truth seems to lie. Of course, that isn't what Harman and Sherman think. Indeed, their central and most striking claim is that, in some cases, one's knowledge might rest on assumptions that are not themselves known but rather justifiably taken for granted. They give the following examples:

(1) You might know that your car is outside in front of your house. This depends on your assuming that your car has not just been stolen, something that you do not know, but rather justifiably take for granted (p. x).

(2) You might know that you will be in Paris next year. This depends on your assuming that you will not die before then, something that you do not know, but rather justifiably take for granted (p. x).

(3) You might know that you are seeing a desk by taking for granted, but without knowing, that you are not a brain in a vat (p. x).

(4) You might know that you will be at the arrivals gate following your flight, although you merely take for granted (and do not know), that the plane will not crash (p. x). 
(5) You might know that you are in your kitchen, although you do not know (but only take for granted) that you are not merely dreaming (p. x).

According to Harman and Sherman, "Part of the explanation of your knowing that your car is presently parked outside is that you justifiably (and truly) take it for granted that the car hasn't been stolen" (p. 2). A question that we might ask at this point: Given the assumption that your car has not been stolen is true, and is something that you justifiably take for granted, what prevents you from knowing the relevant proposition? Not, presumably, that you don't believe that your car has not just been stolen, for Harman and Sherman explicitly allow that you might very well fully believe or accept propositions of this sort (p.2). Nor, presumably, is it that you are not in a position to know because you are in some kind of classic Gettier-type situation, in which your justified true belief rests on a false lemma. So what is it, exactly, that prevents you from knowing that your car has not just been stolen in a case in which you truly believe that proposition on the basis of those considerations which justify you in assuming that it's true? Why are these beliefs falling short of knowledge?

Harman and Sherman are rather coy when it comes to providing the kind of general principles that might shed light on this. They write: "While we agree that it would be nice to provide such principles, we do not see it is any objection to our commonsensical approach that we have failed to do so" (p.18). Fair enough; I agree that not providing principles of the relevant kind is not itself an objection to the account on offer. However, given the examples that they employ throughout the paper, there is a natural thought about what the relevant general principle is. (That is, there is a natural thought about what general principle might explain why you are not in a position to know that your car has not just been stolen, even when that assumption successfully underwrites your knowledge that your car is parked in front of your house.) Namely, your belief that your car has not just been stolen is not sensitive: if in fact your car had just been stolen, you would nevertheless still believe that it had not just been stolen, albeit in that case falsely. On the other hand, your belief that your car is parked in front of your house is sensitive: if you hadn't parked it in front of the house, you would have put it in the driveway (etc.), in which case you would not believe that it is parked in front of the house. The same is 
true, I think, of all of the examples provided by Harman and Sherman of cases in which a proposition is known partially on the basis of a second proposition that is not known but rather taken for granted: belief in the proposition that is known is sensitive, while belief in the proposition that is merely taken for granted is insensitive. (Or at least, it's natural to hear the stories in that way.) So one way in which someone might be led to the account on offer is the following: one might think, with Nozick (1981), that sensitivity (or rather, some suitably-refined sensitivity condition) is a necessary condition for knowledge.

So one obvious question for Harman and Sherman is: is that in fact what you think? If a background commitment to sensitivity (or some principle which entails sensitivity) is not what's driving things, then we would expect to find at least some examples that have the following features: the individual in the example has a non-Gettiered, justified true belief in the assumption that is taken for granted, but her belief (i) is not knowledge, and (ii) is sensitive. Are there such cases? If a commitment to sensitivity is what's driving things, then whether the account is tenable would seem to come down in large part to whether sensitivity (or some suitably refined sensitivity condition) is in fact a necessary condition on knowledge, a question to which a substantial literature is devoted. ${ }^{3}$ (For the record, I think that we have good reasons to suppose that there is no necessary condition on knowledge in the relevant neighborhood, but I won't review those reasons here.)

2. Imagine a theorist who accepts Harman and Sherman's account but who does not think that sensitivity is a necessary condition for knowledge. Such a theorist might tell an alternative story about why one might not be in a position to know some true proposition even if one fully believes it and is justified in assuming that it is true. Specifically, such a theorist might think the following: although it makes sense to talk about one's beliefs as justified and unjustified, and it similarly makes sense to talk about one's assumptions as justified or unjustified, the kinds of considerations that are relevant to whether one is justified in assuming $\mathrm{p}$ (or taking $\mathrm{p}$ for granted) are quite different from the kinds of considerations that are relevant to whether one is justified in believing $\mathrm{p}$. That is:

3 See, e.g., Becker $(2007,2009)$, DeRose (1995), Sosa (1999), Vogel $(1987,2000)$ and Williamson (2000). 
justification for a belief is one thing, justification for an assumption is another, even if it's the same proposition which is both believed and assumed.

In particular, it is at least somewhat plausible to think that whether one is justified in assuming that $p$ is true depends significantly, perhaps even entirely, on the expected utility of doing so. (Although I don't want to attribute this view to Harman and Sherman, it is worth nothing that some of their examples, and what they say about those examples, fit quite nicely with the idea that considerations of expected utility play a significant role here. Consider, for example, what they say about your justified assumption that you are not a brain in a vat: "You realize that much of what you accept rests on such assumptions as that you are not a brain in a vat and you see no benefit in opening an investigation into whether those assumptions are true" [p.6, emphasis mine]). Indeed, I find the following quite plausible:

One is justified in assuming that $\mathrm{p}$ is true only if the expected utility of doing so is at least as high as the expected utility of not making that assumption. ${ }^{4}$

So this would be to think of taking something for granted as an action, or something very similar to an action.

On the other hand, one might think that, with respect to the question of whether a person is justified in believing $\mathrm{p}$, considerations of expected utility simply do not come into play in the same way. If one's evidence overwhelmingly suggests that $p$ is true, then one is justified in believing $\mathrm{p}$, even if the expected utility of doing so is lower than the expected utility of not believing p. Of course, some philosophers have held that there is a kind of justification applicable to beliefs (so-called "pragmatic" or "practical" justification) that depends on practical considerations in this way. On one version of this view, if the reasoning behind Pascal's Wager is correct, then there is a sense in which one is justified in believing that God exists even if one's evidence strongly suggests that there is no such being. I am very skeptical of the idea that there is some kind of "practical" justification that is genuinely applicable to beliefs. ${ }^{5}$ But that's a delicate issue that we can

\footnotetext{
${ }^{4}$ Notice that this candidate necessary condition is consistent with the earlier proposal that one is justified in assuming $p$ only if one knows that $p$ is true.

${ }^{5}$ For an argument, see my (2002).
} 
sidestep here. For if the question is: “why aren't you in a position to know that p, when you justifiably assume that $\mathrm{p}$ in the kinds of cases that Harman and Sherman have in mind?", then it doesn't matter whether there is some kind of justification applicable to beliefs that depends on considerations of expected utility. Rather, what matters is the kind of justification applicable to beliefs that is plausibly thought to be a necessary condition for knowledge. And a very popular idea is that when it comes to the kind of justification required for knowledge, what is at issue is so-called "purely epistemic" justification, the kind of justification that depends on things like the bearing of your total evidence but not on considerations of expected utility. So a theorist who thought this and accepted Harman's and Sherman's account would have a good answer to the question: "Why aren't you in a position to know any true proposition which you fully believe and justifiably assume to be true?" Namely: the kinds of considerations which justify you in assuming that some content is true are not the same kinds of considerations which would justifying you in believing that that content is true, in the sense of 'justification' relevant for knowing.

In fact, I suspect that this is probably not what Harman and Sherman think. For I suspect that at least Harman is too much of a pragmatist to think that there is such a thing as "purely epistemic justification”, which plays an important role in epistemology. But I mention this theoretical option both because I think that it would be interesting to explore, and also because I myself think that the relevant assumptions (viz. whether one is justified in taking something for granted depends on the expected utility of doing so, but whether one is justified in believing the same proposition is not a matter of expected utility) are actually true.

3. Thus far, most of what I've said has been in a constructive as opposed to a critical spirit. I've made some suggestions about different theoretical options that might be pursued by someone who accepts or is attracted to the account on offer. But of course, there's still the question of whether that account is true. Here, whether there is some true strong closure principle is obviously a central issue. I'm significantly more sympathetic to closure than Harman and Sherman. (Although I am less sympathetic than some philosophers, who seem to regard closure as something like a datum, and treat the fact that a given view fails to respect it as a sufficient reason to reject that view.) My reasons 
for thinking that there is some true closure principle are the standard ones. In particular, I've always been quite moved by the problem of so-called "abominable conjunctions", the apparent unacceptability of conjunctions such as the following:

I know that I have hands, but I don't know that I'm not a brain in a vat without hands.

(This example is from DeRose 1995; it's perhaps marginally more difficult than the examples that Harman and Sherman consider in their paper.)

Harman and Sherman are of course well aware of this kind of challenge. In response, they offer a story on which abominable conjunctions can be true but nevertheless sound odd when asserted 'out of the blue' for reasons having to do with pragmatics. (To their credit, they are not content to simply claim that some pragmatic phenomenon is at work here, but provide an interesting story about how the mechanism actually works.) They claim that true abominable conjunctions that sound odd when asserted out of the blue do not sound odd when prefaced with the right kind of explanatory story (pp.16-17). For what it's worth, abominable conjunctions still sound pretty bad to my ear, even when they are prefaced by the kind of speech that Harman and Sherman suggest.

For the record, here is the abominable conjunction mentioned above, preceded by the relevant kind of speech (modeled closely on their (4), p.16):

I do not know whether or not I am a brain in a vat without hands. I think that I have hands. In thinking that I have hands, I assume that I am not a brain in a vat without hands. As far as I can see I am justified in taking that for granted and, given that assumption, I know that I have hands. So I do not know whether or not I am a brain in a vat without hands but I do know that I have hands.

As I said, my own reasons for thinking that some closure principle is true are pretty much the standard ones. ${ }^{6}$ These considerations evidently don't impress Harman and Sherman, so for that reason I won't go on about this too much. But I do want to say something about how their line on "abominable conjunctions" interacts with certain big picture methodological issues about how we should score alternative views in this area.

\footnotetext{
${ }^{6}$ Hawthorne $(2004,2005)$ provides a state of the art overview of the case for closure. Dretske $(2005 \mathrm{a}, 2005 \mathrm{~b})$ is a response.
} 
Although they aren't explicit about their methodology, the approach pursued by Harman and Sherman seems to be very much a "bottom-up" as opposed to "top-down" approach". They don't begin with a commitment to general theoretical principles about knowledge and then evaluate particular claims about what we know and don't know in the light of those principles. Rather, their starting point is what we would ordinarily take ourselves to know: among those things that we assume or take for granted, we would not ordinarily take ourselves to know that we will not be hit by a bus or die of a fatal heart, or that our ticket will lose the lottery, or that our car has not just been stolen (etc.). The task is then to show how these particular judgments can be reconciled with other intuitively compelling, particular judgments: that we do know the car is parked in front of the house, that we will not have enough money to take an unusually large number of trips this year, and so on. At one point, they emphasize that the fact that theories such as Dretske's (1970) and Nozick's (1981) have problems does not undermine the intuitive nature of the knowledge claims that originally motivated those theories (p.13). At the end of the paper, in the context of rejecting the suggestion that it is incumbent upon them to provide more general epistemological principles, they describe their own approach as a "commonsensical" one (p.18). Throughout the paper then, one gets the sense of theorists who are giving a great deal of weight to preserving common sense judgments about the truth of particular knowledge claims. (As opposed to theorists who are prepared to be extremely revisionary about such judgments if they turn out to conflict with more abstract, theoretical principles about knowledge, etc.)

As a methodological matter, I think that this is generally the right way to go, both in epistemology and elsewhere: I'm all for giving a great deal of weight to our considered judgments about particular cases. But I worry that this background picture exacerbates the awkwardness of dealing with abominable conjunctions by classifying them as "true, but pragmatically odd to assert". After all, when we judge that "I know that I have hands, but I don't know that I'm not a handless brain-in-a vat' is false, what we are reacting to are not abstract, general principles about knowledge, but rather particular knowledge claims and how such claims bear on one another. Of course, perhaps the puzzles in this area are so difficult that any theory will ultimately have to give up some very intuitive claims, and appeal to some story involving pragmatic phenomena in order to explain 
away the intuitions that the theory fails to accommodate. But one might think that having to tell such a story about abominable conjunctions is a greater embarrassment for a view that generally privileges (or at least, gives a great deal of weight to) our more low-level particular judgments.

\section{References}

Becker, Kelly (2007). Epistemology modalized. (New York: Routledge).

Becker, Kelly (2009). "Margins for Error and Sensitivity: What Nozick Might Have Said". Acta Analytica (2009) 24:17-31.

Bratman, Michael (1999). Faces of Intention. (Cambridge: Cambridge University Press).

DeRose, Keith (1995). "Solving the skeptical problem". Philosophical Review 104: 1-52.

Dretske, Fred (1970). “Epistemic Operators”, Journal of Philosophy 67.

Dretske, Fred (2005a). "The Case Against Closure”, in Steup and Sosa (2005): 13-26.

Dretske, Fred (2005b). "Reply to Hawthorne”, in Steup and Sosa (2005): 43-46.

Hawthorne, John (2004). Knowledge and Lotteries. (Oxford: Oxford University Press).

Hawthorne, John (2005). "The Case for Closure" in Steup and Sosa (2005): 26-43.

Kelly, Thomas (2002). "The Rationality of Belief and Some Other Propositional Attitudes". Philosophical Studies 110: 163-196.

Nozick, Robert (1981). Philosophical explanations. Cambridge, MA: Harvard University Press.

Sosa, Ernest (1999). "How to defeat opposition to Moore". Philosophical Perspectives 13: $141-153$.

Steup, Mathias and Sosa, Ernest, eds. (2005). Contemporary Debates in Epistemology. (Malden, MA: Blackwell Publishing).

Vogel, Jonathan (1987). "Tracking, closure, and inductive knowledge”. In Luper-Foy (Ed.), The Tossibility of Knowledge: Nozick and his critics (Totawa, NJ: Rowman \& Littlefield): 197-215.

Vogel, Jonathan. (2000). "Reliabilism Leveled". The Journal of Philosophy 97(11): 602623. 
Williamson, Timothy. (2000). Knowledge and Its Limits. (Oxford: Oxford University Press). 